\title{
THE TRANSPORT OF FRUCTOSE BY HUMAN PLACENTA ${ }^{1}$
}

\author{
By DWAIN D. HAGERMAN and CLAUDE A. VILLEE \\ (From the Research Laboratory of the Boston Lying-in Hospital and the Departments of \\ Obstetrics and Biological Chemistry, Harvard Medical School, Boston, Mass.)
}

(Submitted for publication June 10, 1952; accepted August 1, 1952)

The presence of fructose in fetal blood was first definitely established by Bacon and Bell (1). They found, in agreement with earlier investigators (cf. Cole and Hitchcock [2]), that throughout gestation sheep fetal blood contains an appreciable amount of a ketohexose which they characterized as fructose by its optical rotation and by the preparation of derivatives. Subsequent studies (3) by other investigators revealed a difference in the fructose concentrations of maternal and fetal blood, and demonstrated that sheep placenta actively transfers fructose into the fetal circulation; however, no similar evidence for an active transfer of glucose was obtained. In the human being, Orr (4) has shown that umbilical cord blood obtained at the time of birth contains a levo-rotary reducing sugar which gives a positive Seliwanoff test. Previous studies in this laboratory (5) have shown that human placenta actively secretes glucose up to about the twelfth week of gestation after which this ability is usually lost. In the course of studies of the biochemistry of human reproduction, the amount and source of fructose in human fetal blood has been investigated. The present report describes evidence 1) that an infant's blood at the time of birth contains about $4 \mathrm{mgm}$. per cent of fructose, while at the same time the maternal blood contains less; and 2) that the full-term human placenta can secrete fructose.

\section{METHODS}

Analytical. Blood was obtained from the mother and from the umbilical cord immediately following delivery of the placenta, using the usual mixture of ammonium and potassium oxalate as an anticoagulant. For fructose analyses, blood proteins were precipitated by adding an equal volume of 20 per cent cold trichloracetic acid to the blood. For the determination of total reducing sugars ("glucose") the method of Nelson was used (6).

1 This investigation has been aided by grants from the Charles A. King and Marjorie King Fund and from Winthrop-Stearns, Inc.
Using the resorcinol method of Roe as modified by Higashi and Peters (7), control experiments with pure standard solutions of glucose and fructose gave quantitative, reproducible results. With this procedure glucose gives only 0.9 per cent as much color as an equivalent amount of fructose. A few fructose analyses were also done by the diphenylamine method described by Kendrick (8). In this procedure glucose gives 3 per cent as much color as fructose does, so that a larger correction is required for the amount of glucose present and reacting as fructose. In addition, the diphenylamine method gave much higher fructose values than those obtained concurrently by the resorcinol method. For these reasons the resorcinol method was used in the majority of the analyses.

In vitro studies. Placenta slices weighing about 200 mgm. were incubated in Warburg vessels at $37.5^{\circ} \mathrm{C}$. with an atmosphere of 100 per cent oxygen. The medium was a modified Krebs-Ringer phosphate buffer containing $90 \mathrm{mM} / \mathrm{L} . \mathrm{Na}^{+}, 50 \mathrm{mM} / \mathrm{L} . \mathrm{K}^{+}$and $10 \mathrm{mM} / \mathrm{L} . \mathrm{Mg}^{++}$with $100 \mathrm{mgm}$. per cent glucose added as a carbohydrate substrate. The $\mathrm{pH}$ of the buffer was 6.9 at the beginning of the experiment and $6.9 \pm 0.1$ at the end of the two-hour incubation.

Analyses of the medium for total reducing sugar and fructose were performed as described above for blood.

Chromatographic methods. The trichloracetic acid filtrates of cord blood were extracted with ether to remove the organic acid and concentrated in vacuo to a suitable volume. The residues were placed on Whatman No. 1 filter paper and descending chromatograms were developed using $3: 3: 1$ ethyl acetate, water and acetic acid (9). Aniline oxalate was used as a color reagent for locating the sugars on the chromatograms.

\section{RESULTS}

The blood analyses are summarized in Table I. In accordance with the results of other investigators (cf. Smith [10]), the fetal blood sugar content was found to be significantly lower than the maternal (S.E. of the mean difference $=2.8, \mathrm{P}$ less than 0.01). However, the fructose level of the cord blood was 45 per cent higher than that of the maternal blood (S. E. of the mean of the differences $0.2 ; P$ less than 0.01). Thus the term human placenta can apparently transfer fructose by some active process into the fetal blood stream. 
TABLE I

Fructose and glucose content of human fetal and maternal blood

\begin{tabular}{l|c|c|c}
\hline \hline & $\begin{array}{c}\text { Fructose } \\
\text { (resorcinol } \\
\text { method) }\end{array}$ & $\begin{array}{c}\text { Fructose } \\
\text { (Diphenyl- } \\
\text { amine } \\
\text { method) }\end{array}$ & $\begin{array}{c}\text { Glucose } \\
\text { (Nelson) }\end{array}$ \\
\hline $\begin{array}{l}\text { Maternal blood } \\
\text { Cord blood }\end{array}$ & $\begin{array}{l}2.9^{*} \pm 0.1(18) \dagger \\
4.2 \pm 0.3(20)\end{array}$ & $\begin{array}{c}8.6(4) \\
10.4(4)\end{array}$ & $\begin{array}{c}88 \pm 6(9) \\
74 \pm 7(9)\end{array}$ \\
\hline
\end{tabular}

* All values as mean \pm the standard error in $\mathrm{mgm} . / 100$ ml. blood.

t The number in parentheses indicates the number of experiments.

Incubation in vitro demonstrated that placenta does secrete fructose, as summarized in Table II. Although the amounts of fructose secreted are not large, it is clear that placenta possesses the enzyme system, presumably a fructose-6-phosphatase, required for this process.

An alternative hypothesis would be that the higher level of fructose in the fetal blood is brought about by the secretion of fructose by the liver of the fetus. To test this, incubation experiments were performed using rat liver slices instead of placenta slices in the system described above.
These experiments showed that no fructose is secreted by rat liver and render unlikely the hypothesis that human fetal liver can secrete fructose. ${ }^{2}$

It is well known that the resorcinol and diphenylamine procedures are not entirely specific for fructose so other evidence of the chemical identity of the substance reacting as fructose was sought. The absorption spectra of the reaction products of resorcinol with the unknown sugar and with pure fructose were compared (Figure 1). It is clear that genuine fructose and the material measured in blood as fructose give identical products with resorcinol as measured by their spectral absorption characteristics. More direct evidence

2 These incubations were performed in cooperation with Drs. A. Renold and A. B. Hastings.

TABLE II

Glucose consumption and fructose production by human placenta slices incubated in vitro

\begin{tabular}{l|l}
\hline \hline No. of vessels & $30(7$ placentas $)$ \\
Oxygen consumption & $1.7 \pm 0.3^{*} \mathrm{ml} . / \mathrm{gm}$. dry wt. $/ \mathrm{hr}$. \\
Glucose disappearance & $\begin{array}{l}8.0 \pm 0.4 \mathrm{micromoles} / \mathrm{gm} . \text { wet } \\
\text { wt. } / \mathrm{hr} .\end{array}$ \\
Fructose appearance & $\begin{array}{l}0.17 \pm 0.03 \mathrm{micromoles} / \mathrm{gm} . \\
\text { * }\end{array}$ \\
& wet wt. $/ \mathrm{hr}$.
\end{tabular}

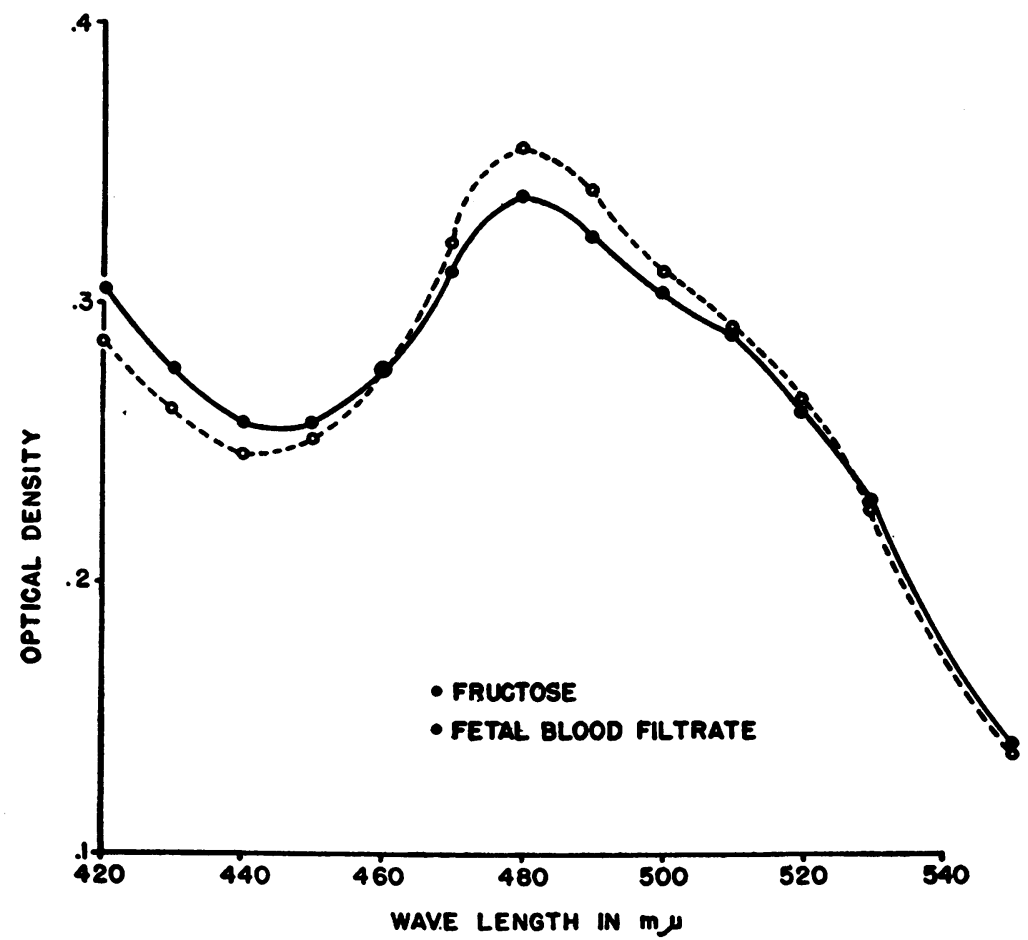

Fig. 1. Absorption Spectra of Resorcinol Reaction Product with Fetal Blood Filtrate and with Pure Fructose (Beckman Spectrophotometer, MODEL D.U.) 
was obtained by paper chromatography. Although the salts and other materials present in the blood filtrates caused rather erratic behavior of the samples on chromatography, a clear separation of the aniline oxalate-reacting material into two components was obtained. Both these components moved more rapidly than did pure glucose and fructose under the same conditions. However, when pure fructose was added to a blood filtrate (adult fasting male) that showed no fructose spot on chromatography before addition of the sugar, the added fructose moved at a rate identical to that of the more rapidly moving component of fetal blood filtrates. This is good evidence that the umbilical cord blood does contain appreciable amounts of fructose. The isolation of fructose and its identification by classical chemical methods were not attempted, since the small amount present would have required extensive manipulation with considerable opportunity for the formation of fructose by isomerization from the glucose present in much larger amounts.

\section{DISCUSSION}

The resorcinol method for fructose analysis is not completely specific, but it is possible to make a correction for the major part of the error, which is caused by glucose. After this correction has been applied, values of $1-2 \mathrm{mgm} . / 100 \mathrm{ml}$. were found for blood from fasting adult males and nonpregnant females. Higher values up to $6 \mathrm{mgm}$./ $100 \mathrm{ml}$. blood were found in non-fasting adults. At the time of birth, maternal blood contains about 2 to $4 \mathrm{mgm}$. $/ 100 \mathrm{ml}$. of fructose while the infant's blood contains more.

Studies on sheep (2) have shown that the fetal blood fructose concentration is quite high during the early months of gestation, and possibly there is a similar high fructose level in human fetal blood early in pregnancy. However, it is diffcult to obtain sufficient human fetal blood earlier in pregnancy for analysis and this has prevented experimental verification of the hypothesis. The diabetic adult human seemingly utilizes parenteral fructose with considerably less difficulty than glucose (11). Studies of human fetal tissues have revealed no striking limitation in their ability to utilize glucose (12), but perhaps a double supply of carbohydrate, entering the cells by the action of two different enzyme systems, is provided for the fetus as a safety measure to reduce the hazards of its early intra-uterine life.

\section{SUM M ARY}

1. Fructose has been identified in human umbilical cord blood on the basis of the absorption spectrum of its resorcinol reaction product and by its behavior on filter paper partition chromatography.

2. Human umbilical cord blood at the time of birth contains about 45 per cent more fructose than does maternal blood at the same time.

3. Human placenta at term is capable of secreting small but significant amounts of fructose when incubated in vitro.

\section{REFERENCES}

1. Bacon, J. S. D., and Bell, D. J., Fructose and glucose in the blood of the foetal sheep. Biochem. J., 1948, 42, 397.

2. Cole, S. W., and Hitchcock, M. W. S., Sugars in the foetal and maternal bloods of sheep. Biochem. J., 1946, 40, ii (51).

3. Huggett, A. St. G., Warren, F. L., and Warren, N. V., The origin of the blood fructose of the foetal sheep. J. Physiol., 1951, 113, 258.

4. Orr, A. P., Laevulose in the blood of the human foetus. Biochem. J., 1924, 18, 171.

5. Villee, C. A., Metabolism of fetal tissues in vitro. Federation Proc., 1952, 11, 302.

6. Nelson, N., A photometric adaptation of the Somogyi method for the determination of glucose. J. Biol. Chem., 1944, 153, 375.

7. Higashi, A., and Peters, L., A rapid colorimetric method for the determination of inulin in plasma and urine. J. Lab. \& Clin. Med., 1950, 35, 475.

8. Kendrick, A. B., Determination of fructose in the presence of glucose in blood and urine by use of diphenylamine. Federation Proc., 1952, 11, 239.

9. Jermyn, M. A., and Isherwood, F. A., Improved separation of sugars on the paper partition chromatogram. Biochem. J., 1949, 44, 402.

10. Smith, C. A., The Physiology of the Newborn Infant. Second edition. 1951. C. C. Thomas, Springfield. xii +348 pp.

11. Miller, M., Drucker, W. R., Owens, J. E., Craig, J. W., and Woodward, H., Metabolism of intravenous fructose and glucose in normal and diabetic subjects. J. Clin. Invest., 1952, 31, 115.

12. Villee, C. A., and Balzer, D. T., Studies on the metabolism of fetal and placental tissues. Biol. Bull., 1951, 101, 195. 